\section{¿QUÉ PASA CON LOS ANUNCIOS EN EL MERCADO LABORAL?}

Por Marcela Perticara, académica FEN UAH y Ph.D. en Economía, U Texas AEtM, Estados Unidos.

Y Mauricio Tejada académico FEN UAH y Ph.D. en Economia, U Georgetown, Estados Unidos.

Desde hace ya varios meses que esperamos con ansias la publicación mensual de temperatura a la situación actual del merla reacción es sistemáticamente la misma: alivio y extrañeza de que la tasa no se hay disparado frente al pobre desempeño de los indicadores del nivel de actividad'. Lo cierto es que este aparente desacople entre la tasa de desempleo y el nivel de actividad no es tal, ya que replica lo sucedido en el marco de otras crisis en la economía chilena: la tasa de desempleo reacciona fuertement a grandes recortes/aumentos en el nivel de actividad, pero permanece relativamente biabs (an asitas am niveles de actividad bajos laun asi acompañando en sentido vidad). Esto puede observarse claramente en el Gráfico 1 donde se hace evidente que -sin conocer los próximos 12 mesesno contamos con suficiente información para sostener este desacoplamiento. Este comportamiento del mercado laboral en el pais es consistente con lo reportado por la literatura. Estimaciones para otros paises sobre la relación empirica entre la tasa de desempleo y la actividad económica (Ley de y de 7,6\% a 4,3\% para los técnicos-profeORun) muestran que aunque la correlación sionales (ver Grafico 3). El empleo asalariaco

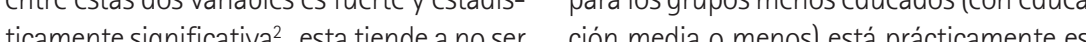
de severidad del ciclo económico ${ }^{3}$ desde mediados del año pasado (ver Gráfico La relativa estabilidad en la tasa de des- 4) El panorama luce más desolador sivemos empleo que se observa en este escenario los cambios en 24 meses. En los últimos 24 de desaceleración (ver Gráfico 2) esconde meses, el empleo asalariado y por cuenta importantes heterogeneidades, que efecti- propia de los trabajadores de más baja califivamente pueden estar respondiendo fuer- cación (sin educación media), decreció 1\% y temente a las pocas expectativas de creci- $\quad 2 \%$ respectivamente: estos trabajadores senmiento. Por ejemplo, si bien el empleo total cillamente están buscando empleo o se han muestra un crecimiento anual de $1,8 \%$ en el pasado a la inactividad. ultimo trimestre movil disponible, hay im- En suma, si bien la tasa de desempleo agreportantes movimientos entre grupos ocu- gada no muestra grandes cambios en respacionales, lo que puede evidenciar que el puesta a la actividad económica, hay bastante mercado si se estaria ajstando palatina- heterogeneidad en la respuesta de distintos 0.98\% en doce meses en tanto que el traba- está precarizando principalmente en los gre jo cuenta propia lo hizo en 21\% Además el pos vulnerables de la población Por supuesto empleo asalariado de los sectores más edu- que los resultados de los primero meses de cados de la población ha tendido a desace- año llevan consigo un componente estaciolerarse sistemáticamente desde mediados nal, no obstante hay señales de deterioro en del año pasado, cortando su crecimiento en el mercado laboral en los últimos 24 meses. doce meses de 13,2\% a 4,3\% para los traba- Esta semana se dio a conocer el nivel de jadores con educación universitaria o más IMACEC para el mes de febrero; el nivel de estable en el tiempo y varia según el grado tancado (e incluso decreciendo ligeramente) El empleo asalariado crece un magro grupos de poblacion Ade ás, a pesar que

actividad mostró un repunte aumentando de Gobierno este mes pueden, en el margen $1.9 \%$ con respecto a febrero del año pasado, generar algún impacto en la capacidad de y $0.8 \%$ con respecto al mes de enero. Estas creación de empleo de la economia, pero no son buenas noticias, pero hasta no ver con- es claro ni esperable que se rompa tan fásolidación de tendencias en los principales cilmente esta inercia. Tampoco es razonable sectores económicos, es un poco prematuro suponer que el precio del cobre se recupera-
hablar de recuperación. Recordemos que va hablar de recuperación. Recordemos que ya rá de manera sustantiva este año, además,
a principios del año 2015 también se experi- el escenario de mayores precios en 2017 a principios del ano 2015 tambièn se experique se desaceleró rápidamente en el segun-

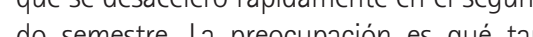
rápido podrí reactivarse el mercado laboral en particular el empleo asalariado de grupos de baja calificación, que ha tenido tasas de crecimiento muy bajas en los últimos meses. El paquete de medidas para impulsar la productividad y ampliar la capacidad de crealgunos bancos de inversión, el precio del algunos bancos de inversion, el precio del año pero dependerá de qué tanto se revierta a desaceleración de la demanda de materias primas de China (según datos del FMII de este mes el crecimiento de China se desacelerará 6.5\% este año y a $6.2 \%$ en 2017 ) y del nivel cimiento de la economía anunciadas por el los últimos dos años de baja.

Gráfico 1. Desvios del crecimiento del IMACEC respeetod
variaciones en la Tasa de Desempleo (12 Meses)

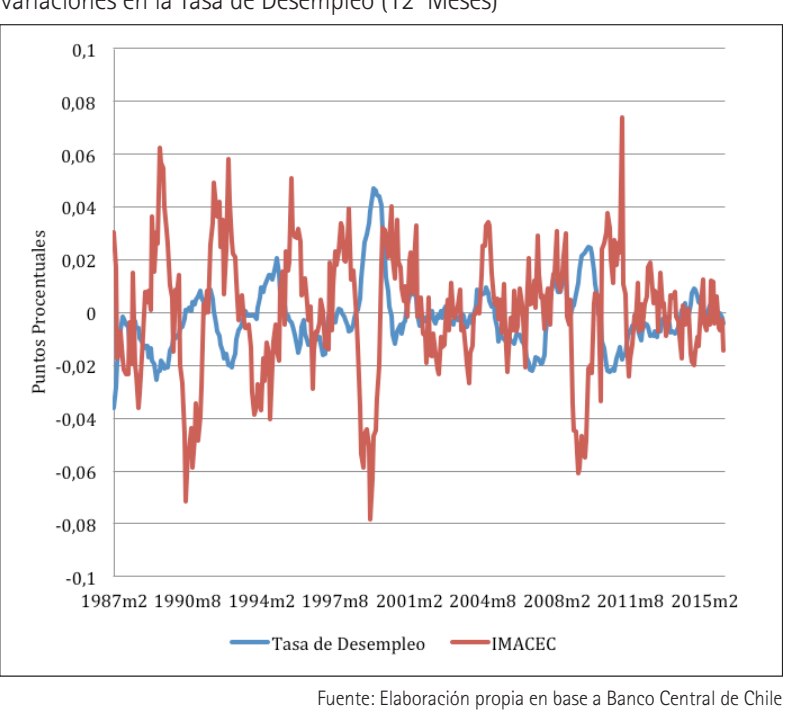

Gráico 3. Tasa de Desempleo por Nivel de Escolaridad

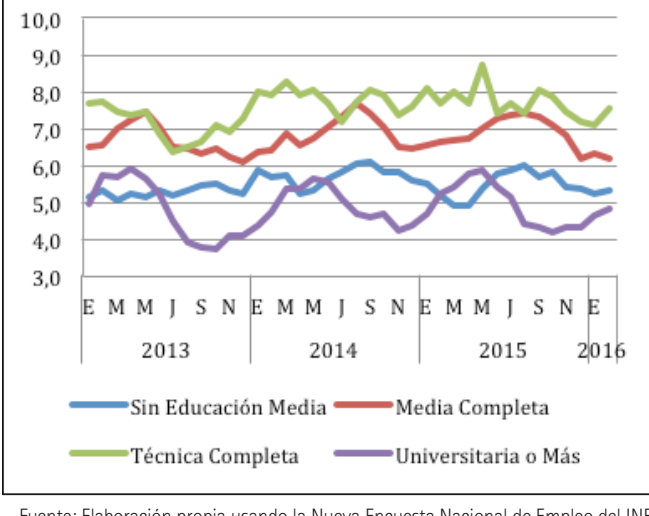

Recién para el mes de febrero; el nivel de actividad respecto a febrero del año pasado, y un $0.8 \%$ con sspecto al mes de enero, pero no es clara aún Is

Tara el caso de Chile estimamos que, en promedio parcentual de crecimiento del IMACEC por sobre sut tendencia, la tasa de desempleo se reduce en se observió una relación de 0.054 en los 905 y has a crisis saíatica, la misma que se redujo a 0.014 durante los 2000 s y hasta la crisis financiera de crisis financierzento a 0.090 en el periodo post ver por ejemplo el capitulo 3 del World Economic Oulook del FMI de abril 2010.

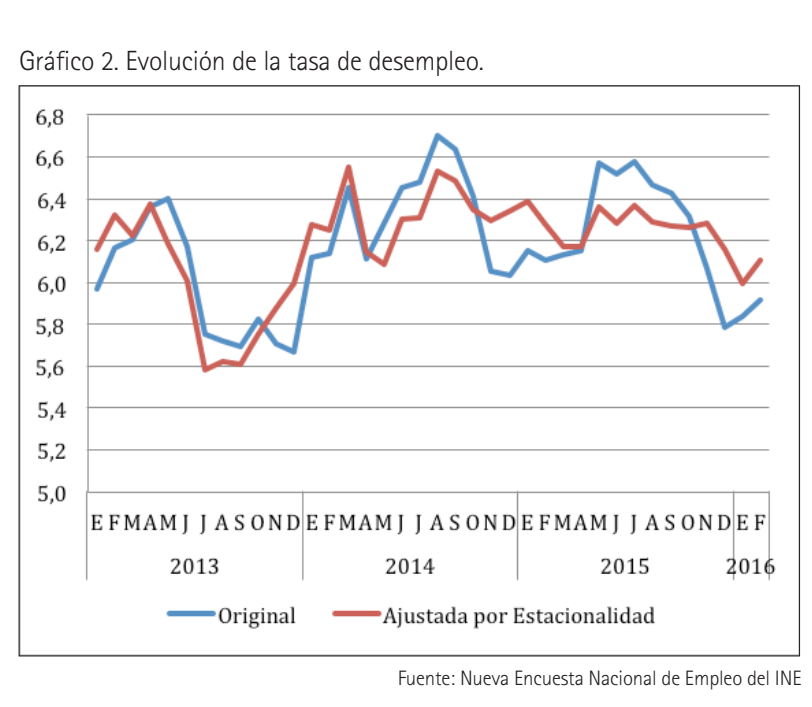

Gráfico 4. Asalariados. Tasa de crecimiento en el empleo por

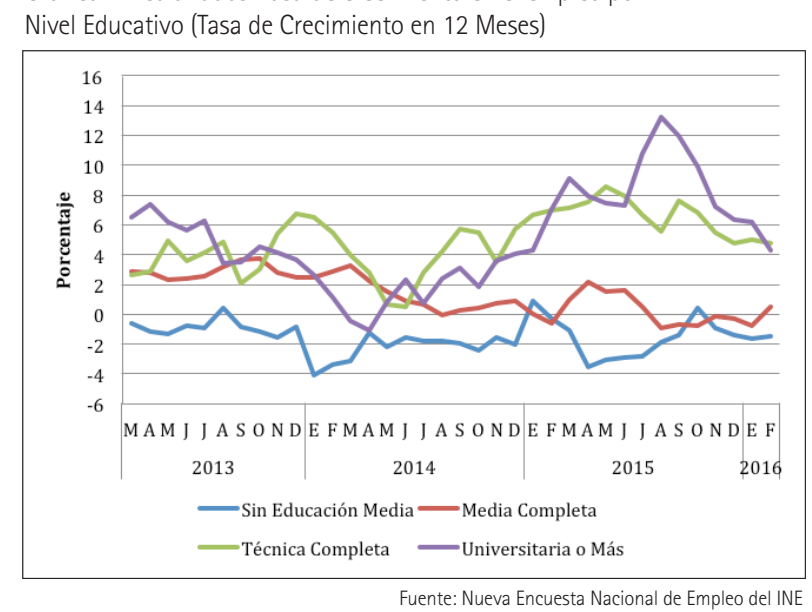

